\title{
CORROSION FATIGUE MECHANISMS IN METALLIC MATERIALS
}

\author{
T. Magnin and D. Delafosse \\ Ecole Nationale Supérieure des Mines de Saint-Etienne, URA CNRS 1884, \\ 158, Cours Fauriel 42023 Saint-Etienne Cedex 2, France
}

\begin{abstract}
Classical approaches of corrosion fatigue damage according to the different electrochemical corrosion domains are presented through their interests and limits. A peculiar attention is paid on the necessity to integrate corrosion-deformation interactions to these modellings. A non exhaustive review of such interactions in corrosion fatigue is made and trends for further researches are emphasized.
\end{abstract}

\section{KEYWORDS}

Corrosion, fatigue, plasticity, electrochemistry, Corrosion-deformation interactions.

\section{INTRODUCTION}

The deleterious effect of aqueous environment on fatigue crack initiation and propagation in metals and alloys has been observed since a long time [1-3]. It is well known that slip bands, twins, interphases, grain boundaries and particles are classical sites for crack initiation and play a role on crack propagation. Moreover, persistant slip bands (PSB)/grain boundaries interactions are often observed to be preferential crack initiation sites during corrosion fatigue $(\mathrm{CF})$, as well as localized pits around metallurgical heterogeneities.

The main need in corrosion fatigue modelling is related to the quantitative approach of local synergetic effects between environment and cyclic plasticity. In this article, quantitative approaches of corrosion fatigue damage from different electrochemical conditions are presented with respect to their interests and their limits. Then improvements of such models are given through corrosion-deformation interaction effects recently analysed.

\section{Classical Approaches of Corrosion Fatigue Damage}

Electrochemical corrosion can be schematised as an 'electronic pump or an electronic circuit' related to oxidation and reduction reactions :

$$
\begin{aligned}
& \mathrm{M} \rightarrow \mathrm{M}^{\mathrm{n}+}+\mathrm{ne}^{-}: \text {anodic dissolution } \\
& \left.\begin{array}{r}
2 \mathrm{H}_{2} \mathrm{O}+\mathrm{O}_{2}+4 \mathrm{e}^{-} \rightarrow 4 \mathrm{OH}^{-} \\
2 \mathrm{H}^{+}+2 \mathrm{e}^{-} \rightarrow \mathrm{H}_{2}
\end{array}\right\} \text { cathodic reactions }
\end{aligned}
$$

together with cation hydrolysis reaction : $\mathrm{M}^{\mathrm{n}+}+n \mathrm{H}_{2} \mathrm{O} \rightarrow \mathrm{M}(\mathrm{OH})_{\mathrm{n}}+n \mathrm{H}^{+}$. 
$\mathrm{M}^{\mathrm{n}+}$ is a solvated ion, $\mathrm{e}^{-}$is an electron and $n$ represents the ion state of charge. The electrons, liberated by the oxidation, must flow through the material $\mathrm{M}$ to be consumed in an appropriate cathodic reaction. Beyond a solubility limit, precipitates of hydroxide or hydrated oxide are formed, and this surface film can provide a barrier to further dissolution. In fact there are two film formation mechanisms : the dissolution / precipitation mechanism addressed before and also the solid state oxidation process $\mathrm{M}+\mathrm{H}_{2} \mathrm{O} \rightarrow \mathrm{MO}+2 \mathrm{H}^{+}+2 \mathrm{e}^{-}$. Some films are named 'passive', for stainless steels or aluminium alloys for instance. Theses films will play an important role in environment sensitive crack initiation and fracture. Under thermodynamic equilibrium conditions, the film stability may be inferred from $\mathrm{E}=\mathrm{f}(\mathrm{pH})$ diagrams, where $E$ is the electrical potential related to the chemical free energy $G$ by the relation : $G=-n$ $\mathrm{EF}$, and $\mathrm{F}$ is the Faraday's number. At equilibrium, one can define the 'electrode potential' (related to $\Delta \mathrm{G}$ ) and the current density I ( $\mathrm{I} \sim \mathrm{e}^{-\Delta \mathrm{G}^{*} / \mathrm{RT}}$ where $\Delta \mathrm{G}^{*}$ is the activation energy of dissolution). Thus corrosion fatigue damage is closely dependent of the electrochemical domaine from cathodic to anodic ones.

Crack initiation is often related to pits which act as stress concentrators during fatigue. If such pits reach a critical depth $\mathrm{d}_{\mathrm{CL}}$, a fatigue crack can develop. The critical depth is then a function of the applied stress range [4].

Let us suppose the following conditions :

- constant corrosion conditions ( $\mathrm{pH}$, concentration of bulk solution)

- constant alternating load, $\mathrm{d} \Delta \mathrm{P} / \mathrm{dt}=0$

- constant loading frequency $\mathrm{d} v / \mathrm{dt}=0$

It is well established that growth kinetics of corrosion pits are determined by a simple power law :

$$
\mathrm{d}_{\mathrm{L}}(\mathrm{t})=\mathrm{C}\left(\mathrm{t}-\mathrm{t}_{0}\right)^{\beta}, \mathrm{t}>\mathrm{t}_{0}
$$

where $t_{0}$ is the incubation time for pit nucleation. If the pit depth reaches the critical value :

$$
\mathrm{d}_{\mathrm{L}}(\mathrm{t})=\mathrm{d}_{\mathrm{CL}}
$$

corrosion fatigue crack initiation occurs. The critical pit depth $d_{C L}$ depends on the applied stress range $\Delta \sigma_{0}$, cyclic yield strength $\sigma_{\mathrm{FC}}$ (which can be different than the tensile yield strength) fatigue crack growth threshold $\Delta \mathrm{K}_{0}$, and the geometry of the specimen, expressed in terms of a geometrical factor $\mathrm{G}$. It can be calculated by elastic-plastic fracture mechanisms based on the Dugdale model [5]. $\mathrm{d}_{\mathrm{CL}}$ is then given by the following equation :

$$
\mathrm{d}_{\mathrm{CL}}=\frac{\cos \left(\pi \Delta \sigma_{0} / 4 \sigma_{\mathrm{FC}}\right) \cdot \pi \Delta \mathrm{K}_{0}^{2}}{32 \mathrm{G}^{2} \sigma_{\mathrm{FC}}^{2}\left[1-\cos \left(\Delta \pi \sigma_{0} / 4 \sigma_{\mathrm{FC}}\right)\right]}
$$

The number of cycles to initiate a corrosion fatigue crack under pitting conditions is, by combining the previous equations with $\mathrm{N}=\mathrm{t} . \mathrm{v}$ :

$$
\mathrm{N}_{\mathrm{i}}=\mathrm{v}\left[\mathrm{t}_{0}+\left(\mathrm{d}_{\mathrm{CL}} / \mathrm{C}_{2}\right)^{1 / \beta}\right]
$$

Such approaches have been successfully applied to the fatigue crack initiation in a fcc Fe-Mn-Cr alloy cyclically deformed at low strain rate in a $\mathrm{Cl}^{-}$solution. Nevertheless, the main problem is related to the fact that the coefficients $C$ and $\beta$ of the pit kinetics are often not constant during cycling : it is a clear example of a cooperative effect between plasticity and electrochemistry which needs finer analyses. Crack propagation can be modelled in the same way. Anodic dissolution has been shown to occur preferentially in slip bands at the very near crack tip. This localized dissolution process is taken into account by the slip dissolution-model which is based on the fact that for many alloys in different solutions the crack propagation rate is proportional to the oxidation kinetics. Thus, by invoking the Faraday's law, the average environmentally-controlled crack propagation rates $\bar{V}_{t}$ for passive alloys is related to 
oxidation charge density passed between film rupture events, $\mathrm{Q}_{\mathrm{f}}: \overline{\mathrm{V}}_{\mathrm{t}}=\frac{\mathrm{M}}{\mathrm{n} \rho \mathrm{F}} \mathrm{Q}_{\mathrm{f}} \frac{1}{\mathrm{t}_{\mathrm{f}}}$ where $\mathrm{t}_{f}$ is the film rupture period. Thus $\overline{\mathrm{V}}_{\mathrm{t}}=\frac{\mathrm{M}}{\mathrm{n} \rho \mathrm{F}} \mathrm{Q}_{\mathrm{f}} \frac{\dot{\varepsilon}}{\varepsilon_{\mathrm{f}}}$ where $\dot{\varepsilon}$ is the strain rate and $\varepsilon_{f}$ the strain for film rupture (about $10^{-3}$ ). If we take a classical law for current transients at the crack tip,

$$
\mathrm{Q}_{\mathrm{f}}=\mathrm{i}_{0} \mathrm{t}_{0}+\int_{\mathrm{t}_{0}}^{\mathrm{t}_{\mathrm{f}}} \mathrm{i}_{0}\left(\frac{\mathrm{t}}{\mathrm{t}_{0}}\right)^{-\beta} \mathrm{dt},
$$

Then, for $\mathrm{t}_{f}>\mathrm{t}_{0}, \beta>0$,

$$
\overline{\mathrm{V}}_{\mathrm{t}}=\frac{\mathrm{Mi}_{0} \mathrm{t}_{0} \dot{\varepsilon}}{\mathrm{n} \rho \mathrm{F}(\beta-1) \varepsilon_{\mathrm{f}}}\left[\beta-\left(\frac{\dot{\varepsilon} \mathrm{t}_{0}}{\dot{\varepsilon}_{\mathrm{f}}}\right)^{\beta-1}\right]
$$

Even if mechanical analyses give good approximations for $\dot{\varepsilon}$ at the crack tip, some problems still remain with the previous equation. In particular, the value of $\beta$ evolves all along cycling [5]. But the main effect is in fact related to localized corrosion-deformation interactions. It has been shown that vacancy generation at crack tip due to localized dissolution can induce cyclic softening effects and that hydrogen absorption which can be also coupled to localized dissolution can also enhance the local cyclic plasticity [5]. It is why improvement of CF predictive laws are needed even if $\mathrm{V}_{\mathrm{t}}$ can be adjusted from equation (6) which is still today very useful. Moreover, films related to solid state oxidation $\left(\mathrm{M}+\mathrm{H}_{2} \mathrm{O} \rightarrow \mathrm{MO}+2 \mathrm{H}^{+}+\right.$ $\left.2 \mathrm{e}^{-}\right)$can also play a role on crack advance. This needs further studies to be quantitatively precised.

\section{Corrosion-deformation interactions}

To improve previous modellings, corrosion-deformation interactions during fatigue must be taken into account. Following examples are given in this way.

Influence of cyclic plasticity on electrochemical reactions

PSB and intense slip bands are very prone to specific dissolution, not only for passivated alloys but also in conditions of generalised dissolution as shown on Figure 1 for copper single crystals in $\mathrm{NaClO}_{4}$ solution [6].

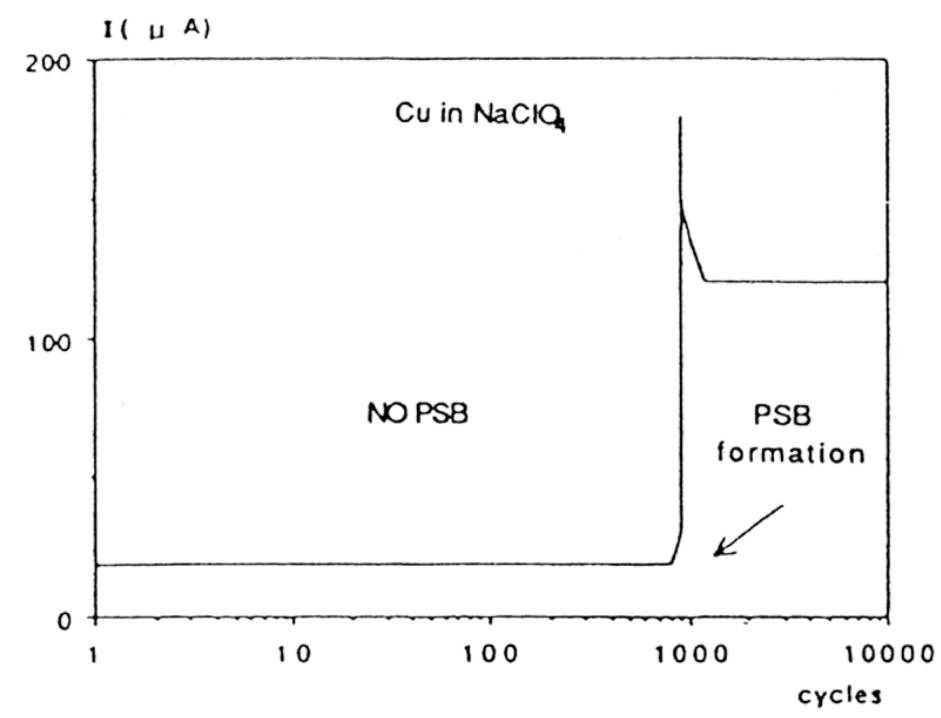

Figure 1: Influence of the PSB formation on the dissolution current for $\mathrm{Cu}$ single crystals in $\mathrm{NaClO}_{4}[6]$. 
As soon as the PSB form, the anodic current increases even though the applied plastic strain remains constant. This effect is not only related to the localisation of the cyclic plasticity but also to the influence of the dislocation microstructure of PSB on the free entergy of dissolution $(-\Delta \mathrm{G})$ and the energy of activation $\left(\Delta \mathrm{G}^{*}\right)[5]$. Moreover cyclic plasticity has been also shown to often promote localised pitting well below the pitting potential without stress [5]. For the ferritic Fe-26 Cr-1Mo stainless steel in $3.5 \%$ $\mathrm{NaCl}$ solution, a high strain rate $\dot{\varepsilon}$ promotes strain localisation at grain boundaries, which induces an intergranular pitting for an applied potential of about $400 \mathrm{mV}$ below the pitting potential without stress effect [5].

The applied strain rate (or frequency) is a very sensitive parameter for CF damage, and particularly for crack initiation. The following example can be given for an Al-Li 8090 alloy in $\mathrm{NaCl}$ solutions. The number of cycles to crack initiation $\mathrm{N}_{\mathrm{i}}$ is defined as the number of cycles to obtain a rapid $3 \%$ decrease of the saturation stress [5]. At high strain rate $\left(\dot{\varepsilon}>5 \times 10^{-3} \mathrm{~s}^{-1}\right)$, the anodic dissolution occurs at slip band emergence and induces an enhancement of the transgranular mechanical microcracking. At medium strain rate ( $5 \times 10^{-5} \mathrm{~s}^{-1}<\dot{\varepsilon}<5 \times 10^{-3} \mathrm{~s}^{-1}$ ), pitting is favoured and responsible for crack initiation. So when the plastic strain decreases, pitting is more profuse (because of time) and the reduction in the fatigue life to crack initiation is more pronounced in comparison to air. At low strain rate $\left(5 \times 10^{-6} \mathrm{~s}^{-1}<\dot{\varepsilon}<10^{-5} \mathrm{~s}^{-1}\right)$, the fatigue time to initiation increases by blunting of the mechanically formed microcracks because of generalised pitting which acts as general corrosion. At very low strain rate $\left(\dot{\varepsilon}<5 \times 10^{-6} \mathrm{~s}^{-1}\right) \mathrm{CF}$ crack initiation occurs by intergranular stress corrosion due to localized dissolution at grain boundaries. The rapid occurrence of SCC induces a marked decrease of $\mathrm{N}_{\mathrm{i}}$.

\section{Softening effect due to anodic dissolution}

$\mathrm{CF}$ tests on smooth specimens were performed at room temperature on a $316 \mathrm{~L}$ austenitic stainless steel in a $0.5 \mathrm{~N} \mathrm{H}_{2} \mathrm{SO}_{4}$ solution at different electrochemical potentials and for a prescribed plastic strain amplitude of $4 \times 10^{-3}\left(\dot{\varepsilon}=10^{-2} \mathrm{~s}^{-1}\right)$. The depassivation-repassivation process occurs in a very regular way, well before any microcracks can form [5]. It is of particular interest to follow the evolution of the maximum flow stress in the corrosive solution at free potential and at imposed cathodic potential, and to compare this evolution with that observed in air (Figure 2). It clearly appears that :
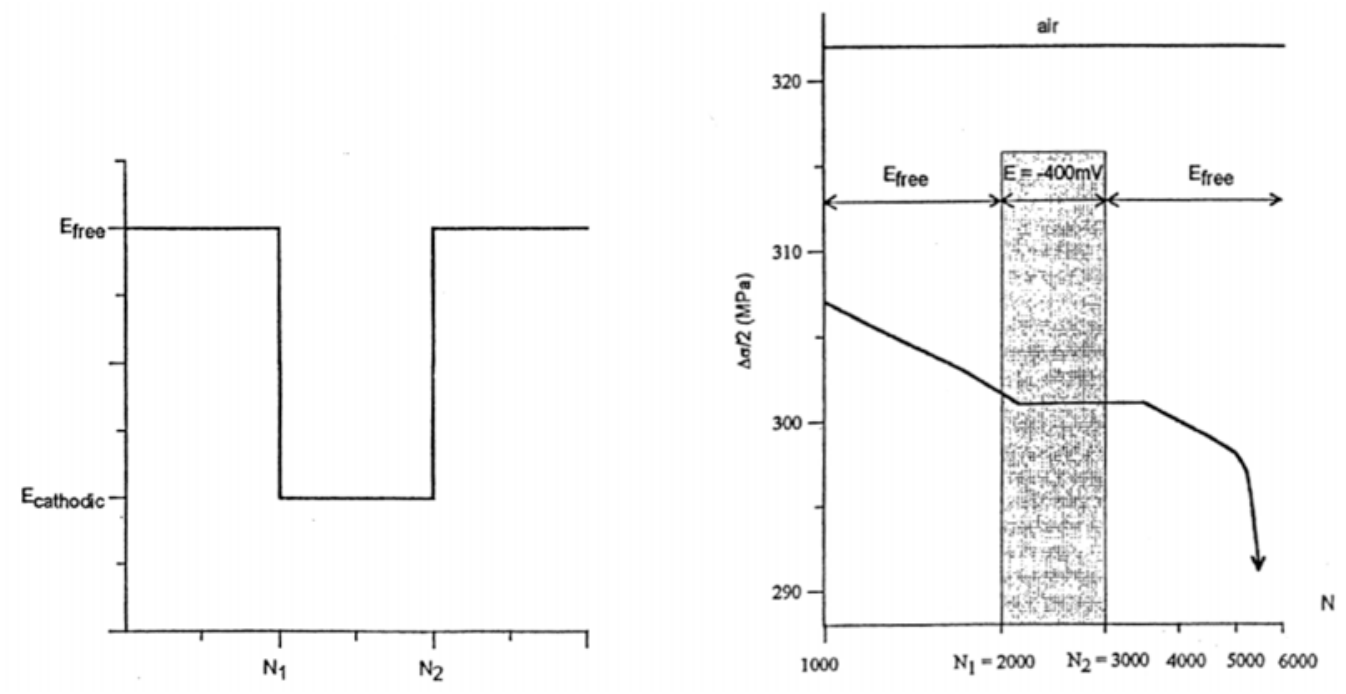

Figure2: Evolution of the peak stress $\Delta \sigma / 2$ during cycling in a $0.5 \mathrm{~N} \mathrm{H}_{2} \mathrm{SO}_{4}$ solution at free potential, for $\frac{\Delta \varepsilon \mathrm{p}}{2}=4 \times 10^{-3}$ and $\dot{\varepsilon}=10^{-2} \mathrm{~s}^{-1}$, compared to the air behaviour. 
(i) a cyclic softening effect occurs at the free potential in comparison to the behaviour in air.

(ii) this softening effect disappears when the cathodic potential is applied (and the anodic dissolution is markedly reduced), after about 150 cycles.

(iii) the softening effect then occurs in the same way when the free potential is re-established.

(iv) a delay in the evolution of the flow stress with regard to the number of cycles for which a potential change is imposed can be observed for the free potential to the cathodic potential change (and vice-versa). This effect has been also observed during creep in corrosive solutions for copper [5]. It corresponds to the time during which vacancies due to dissolution are still acting on the dislocation mobility. The macroscopic cycling softening effect observed in $\mathrm{H}_{2} \mathrm{SO}_{4}$ solution at room temperature (which is not due to microcracking) is very relevant to take quantitatively into account the local dissolution-deformation interactions which will lead to the fatigue crack initiation process.

An example of mechanical and electrochemical coupling effects : the CF crack initiation mechanisms of a two - phase stainless steel in $\mathrm{NaCl}$ solutions

Mechanical and electrochemical coupling effects are generally the key for understanding the crack initiation mechanisms in multiphase alloys. This is clearly illustrated for a duplex $\alpha / \gamma$ stainless steels (without nitrogen) in a 3.5\% $\mathrm{NaCl}$ solution at $\mathrm{pH} 2$ and free potential [5]. At low plastic strain amplitude, the softer $\gamma$ phase is depassivated but this phase is cathodically protected by the non-plastically deformed $\alpha$ phase. This coupling effect reduces the dissolution of the $\gamma$ phase and delays CF damage, which is not the case at higher strain amplitude when the $\alpha$ phase is also depassivated by slip band emergence.

Observations of the crack initiation sites by scanning electron microscopy show [5] that at low plastic strain amplitudes $\left(\Delta \varepsilon \mathrm{p} / 2<10^{-3}\right)$ for which the fatigue resistance of the $\alpha-\gamma$ alloy is close to that of the $\gamma$ alloy, cracks nucleate only in the austenitic phase but, at higher strain amplitudes $\left(\Delta \varepsilon_{\mathrm{p}} / 2>10^{-3}\right)$, the first cracks nucleate principally in the ferritic phase. The excellent CF resistance of duplex stainless steels (for $\Delta \varepsilon_{\mathrm{p}} / 2<10^{-3}$ ) can then be understood through the electrochemical and mechanical coupling effects on crack initiation processes.

\section{Hydrogen effects on cyclic plasticity}

Figure 3 shows the well-established cyclic stress-strain curves of nickel single crystals oriented for single slip, with a plateau region corresponding to persistant slip bands [7]. In the low amplitude range, the dislocation pattern is built up predominantly of elongated and fragmented edge dislocation dipole loops which frequently cluster into dense bundles (the veins). During cyclic hardening, the veins develop and become denser. At a critical threshold stress level, the vein structure becomes locally unstable and gradually gives thin lamellae of persistant slip bands (PSB's) which lie roughly parallel to the glide plane. Cyclic deformation becomes localized to a large extent in the PSB's which are softer than the so-called matrix of veins in which they are embedded.

Hydrogen has be shown to enhance the dislocation mobility in nickel [5] and to promote planar slip. Hovewer, the ease of cross slip is known to be an essential factor facilitating the development of PSB's [1]. The elimination of the screw dislocations by cross slip is a major prerequisite for providing the simple edge multipole dislocation arrangement that appears for undergoing the structural changes leading to PSB's. Moreover, the saturation stress in the PSB's regime is related to the equilibrium between multiplication and annihilation of dislocations which can then be modified by the presence of hydrogen.

Increasing strain amplitudes are applied (Figure 3) to obtain the cyclic stress-strain curves as a function of hydrogen content (from less than $1 \mathrm{ppm} w \mathrm{wt} \%$ in pure nickel to $23 \mathrm{ppm} w \mathrm{wt} \%$ in pre-charged specimens). The following remarks can be made : (i) A plateau region is observed whatever the hydrogen content, but the corresponding saturation stress is lowered in the presence of hydrogen. Moreover a sligth increase of the critical $\gamma p$ for the beginning of the plateau regime seems to be shown with hydrogen ; (ii) A more 
marked difference in the value of the saturation stresses is observed in the vein structure region at low strain amplitudes than in the PSB's domain.

Because of a decrease of the cross slip ability in presence of hydrogen [8], nickel single crystals oriented for single slip exhibit different cyclic stress-strain curves according to the hydrogen content. In the low strain amplitude domain, saturation is reached faster in presence of hydrogen. Such effect can be interpreted in terms of new equilibrium between bundles and mobile screw segments between the veins, which leads to a lower value of the saturation stress. A softening effect due to hydrogen is observed when PSB are formed in the plateau region, whatever the applied strain amplitude. It can be interpreted in terms of decrease of the internal shear stress in PSB walls, which induces a decrease of $\tau_{\mathrm{s}}$.

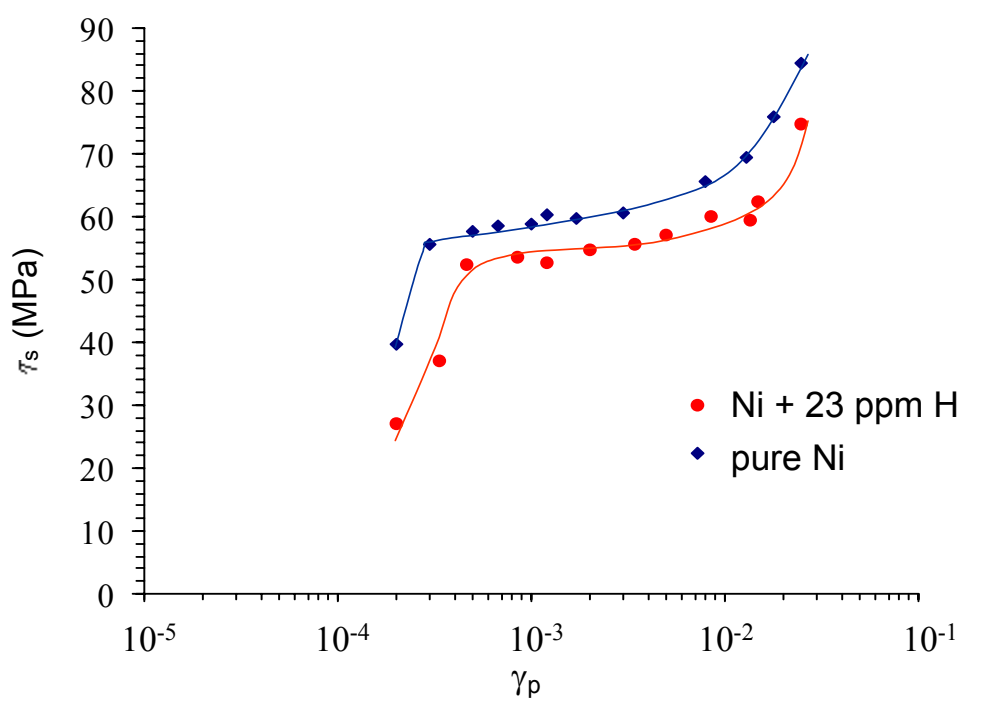

Figure 3: Effect of applied $\gamma p$ on the cyclic hardening curves of [153] nickel single crystals with and without hydrogen.

Such effects of hydrogen on plasticity must be taken to into account in modellings. Hydrogen assisted cracking is often invoked, particularly for bec materials but also together with anodic dissolution for fcc alloys. Figure 4 schematizes a hydrogen assisted cracking event. Interactions between a discretized dislocation array and the crack tip under an applied stress produce a maximum stress field from behind the tip. When the hydrogen concentration reaches a critical value, a microcrack is nucleated because either the local cohesive strength is reduced, dislocation motion is blocked in the hydrogen-enriched zone, or both. The microcrack arrests about $1 \mu \mathrm{m}$ ahead of the original location of the tip and these processes then repeat leading to discontinuous microcracking.

Other mechanisms have been proposed, particularly the hydrogen-induced plasticity model for precipitates containing materials such as Al-Zn-Mg alloys [9]. Absorbed hydrogen atoms weaken interactomic bonds at crack tip and thereby facilitates the injection of dislocations (alternate slip) from crack tip. Crack growth occurs by alternate slip at crack tips which promotes the coalescence of cracks with small voids nucleated just ahead of the cracks. In comparison to the behaviour in neutral environments, the $\mathrm{CF}$ crack growth resistance decreases as the proportion of dislocation injection to dislocation egress increases. More closely spaced void nuclei and lower void nucleation strains should also decrease the resistance to crack growth in $\mathrm{CF}$. This mechanism is proposed for $\mathrm{Al}-\mathrm{Zn}-\mathrm{Mg}$ alloys and is highly supported by observations that environmentally assisted cracking can occur at high crack velocities in materials with low hydrogen diffusivities and that the characteristics of cracking at high and low velocities are similar. 


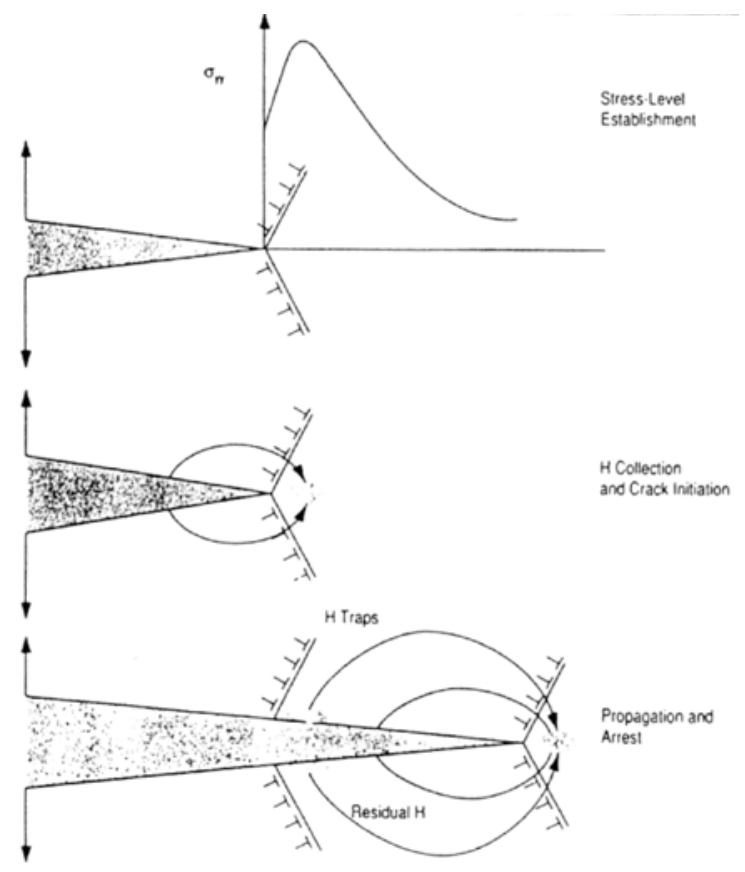

Figure 4: Schematic illustration of hydrogen assisted cracking mechanism [10].

\section{CONCLUDING REMARKS}

The analysis of CF micromechanisms related to anodic dissolution together with hydrogen effects is under progress but needs to be more quantitative through the localized corrosion deformation interactions. The trends for future researches are mainly related to :

(1) the modelization of crack tip chemistry,

(2) the quantitative analysis of corrosion-deformation interactions at CF crack tip (scale of $1 \mu \mathrm{m}$ ) according to the electrochemical conditions,

(3) a comparison between $\mathrm{CF}$ and SCC based on a detailed analysis of micromechanisms near the fatigue threshold,

(4) developments of numerical simulations at mesoscopic scales.

These researches are needed to propose more relevant predictive laws for CF damage based on physicochemical controlling factors.

\section{References}

1. Laird, C. and Duquette, D.J. (1972) Corrosion Fatigue, Nace, New York.

2. Patel, C. (1977), Corr. Sci., 21, 145.

3. Gangloff, R.P. and Duquette, D.J., in : Chemistry and Physics of Fracture, Nijhoff.

4. Mueller, M. (1982) Met. Trans, 13A, 649.

5. Magnin, T. (1996), Advances in corrosion-deformation interactions, Trans. Tech. Publ.

6. Yan, B.D., Farrington, G.C. and Laird, C. (1985) Acta Met., 33, 9, 1593.

7. Mughrabi, H., Ackermann, F. and Herz, K. (1979) in : Fatigue Mechanisms, pp 69-105, J.T. Fong Ed., ASTM STP 675, Philadelphia.

8. $\quad$ Delafosse, D., Château, J.P. and Magnin, T. (1999) J. Phys. IV, 251.

9. Lynch, S.P. (1998) Acta Met., 36, 2639.

10. Gerberich, W.W. (1993) in : Corrosion-Deformation Interactions, pp 325-354, T. Magnin and J.M. Gras Ed., Les Editions de Physique. 